\title{
Effects of Gasification Properties of a combustible on flame Spread Over its Surface
}

TAKESHI SUZUKI and TOSHISUKE HIRANO

Department of Reaction Chemistry

The University of Tokyo, Tokyo, Japan

\section{ABSTRACT}

An experimental study of flame spread over the surface of a filter paper sheet soaked with a combustible liquid was performed to obtain knowledge of the effects of gasification properties on flame spread phenomena. Gasification properties of paper sheets were controlled by changing a soaking liquid selected from normal paraffins, ranging in carbon number from 8 to 13. Flame spread rate increased as the boiling temperature of the soaking liquid decreased. The increasing rate of flame spread rate with decreasing of the boiling temperature became large as the boiling temperature decreased. Flame spread rate decreased as the paper sheet thickness increased. The decreasing rate of flame spread rate with increasing of the thickness became small as the boiling temperature decreased or the thickness increased.

KEYWORDS: Flame spread, Liquid-soaked solid burning

Fire physics, Heterogeneous combustion

\section{NOMENCLATURE}

d - paper sheet thickness

L - distance from an arbitrary horizontal line on the paper sheet along it

m - mass burning rate 
- temperature

$\mathrm{T}_{\mathrm{b}} \quad$ - boiling temperature of soaking liquid

$\mathrm{T}_{\mathrm{i}} \quad$ - initial temperature

$\mathrm{T}_{\mathrm{p}} \quad$ - pyrolysis temperature of solid

$\Delta \mathrm{T} \quad-\mathrm{T}_{\mathrm{b}}-\mathrm{T}_{\mathrm{i}}$

$t$ - time from passing of the leading flame edge across the line $\mathrm{L}=0$

$\mathrm{x}$ - distance along the paper surface from the leading flame edge

$\mathrm{V}$ - flame spread rate

\section{GREEK}

$\alpha \quad$ - inclined angle

$\rho \quad$ - paper sheet density

\section{INTRODUCTION}

Knowledge of flame spread over combustible solids is necessary for basic understanding of the process of fire development, so that a number of studies on this subject have been performed[1-7]. In these studies, flame spread phenomena have been shown to depend on various variables such as direction of flame spread[8-12], external radiation [10,13,14], surrounding air flow $[12,13,15-18]$, and combustible solid thickness[19-21]. Despite the gains achieved through these studies, the ambiguities remain on the mechanisms controlling flame spread. In the process of fire development, flames necessarily spread across material surfaces of various properties. The most important properties that influence flame spread phenomena must be of material gasification. However, only a few studies have been performed on the effects of material gasification on flame spread phenomena[21]. To explore such effects, a combustible material whose gasification properties are controllable is suitable. A porous material soaked with a combustible liquid is one of such materials and it was selected for the present study. Gasification properties of a liquid soaked porous material can be varied by changing the liquid and porous material[22,23]. Since the objective of this study is to accumulate knowledge of flame spread over combustible solids, a combustible porous material is preferable to a non-combustible one. In the present study, therefore, a filter paper sheet is used as a porous material. Paper sheets of uniform quality and different thicknesses can be obtained easily, and a large number of data on flame spread over paper sheets are available. As combustible liquids, with which paper sheets are soaked, normal paraffins of carbon numbers between 8 and 13 are used, because their properties are well-known.

Combustibles of wide ranges of properties can be prepared by using the present method, 
TABLE 1 PROPERTIES OF LIQUIDS

\begin{tabular}{lccr}
$\begin{array}{l}\text { Chemical } \\
\text { Formula }\end{array}$ & $\begin{array}{l}\text { Molecular } \\
\text { Weight }\end{array}$ & $\begin{array}{l}\text { Boiling } \\
\text { Temperature } \\
(0.1 \mathrm{MPa})\end{array}$ & $\begin{array}{r}\text { Density } \\
\left(20{ }^{\circ} \mathrm{C}\right) \\
\end{array}$ \\
& \multicolumn{3}{c}{$\mathrm{g} / \mathrm{cm}^{3}$} \\
$\mathrm{C}_{8} \mathrm{H}_{18}$ & 114.2 & 125.6 & 0.702 \\
$\mathrm{C}_{9} \mathrm{H}_{20}$ & 128.2 & 150.7 & 0.717 \\
$\mathrm{C}_{10} \mathrm{H}_{22}$ & 142.2 & 174.1 & 0.730 \\
$\mathrm{C}_{11} \mathrm{H}_{24}$ & 156.3 & 195.8 & 0.740 \\
$\mathrm{C}_{12} \mathrm{H}_{26}$ & 170.3 & 216.2 & 0.748 \\
$\mathrm{C}_{13} \mathrm{H}_{28}$ & 184.3 & 235.4 & 0.756
\end{tabular}

and behaviour of flame spread over solid combustibles of various gasification properties can be simulated. This study will offer knowledge useful to predict fire development.

\section{EXPERIMENTAL}

Paper sheets used in the present experimental study were of six different thicknesses, i.e., $0.18 \mathrm{~mm}, 0.20 \mathrm{~mm}, 0.23 \mathrm{~mm}, 0.26 \mathrm{~mm}, 0.40 \mathrm{~mm}$, and $0.68 \mathrm{~mm}$, and the combustible liquids used were octane, nonane, decane, undecane, dodecane, and tridecane. The properties of the liquids are listed in Table 1[24]. A paper sheet was soaked in the liquid in a tray. The density $\rho$ of the paper sheet was varied by controlling mass of soaking liquid by pressing the liquid soaked paper sheet between dry paper sheets. The density of a liquid soaked paper sheet was calculated by dividing its mass by its surface area and thickness.

The flame spread facility shown in Fig.l was used to hold the filter paper sheet at an arbitrary inclined angle $\alpha$ during a test. A paper sheet of $4 \mathrm{~cm} \times 14 \mathrm{~cm}$ in the surface area was clamped between pairs of metal straps, leaving $3 \mathrm{~cm}$ wide exposed to burn. The temperature of the paper surface was measured with a $\mathrm{Pt} / \mathrm{Pt}-13 \% \mathrm{Rh}$ thermocouple (wire diameter, $0.1 \mathrm{~mm}$ ). The inclined angle from a horizontal surface is in the range from $90^{\circ}$ (vertically downward) to zero (horizontal). Flame spread phenomena were recorded by a 35 mm camera and a video camera and analyzed.

\section{RESULTS AND DISCUSSION}

\section{Behaviour of spreading flames}




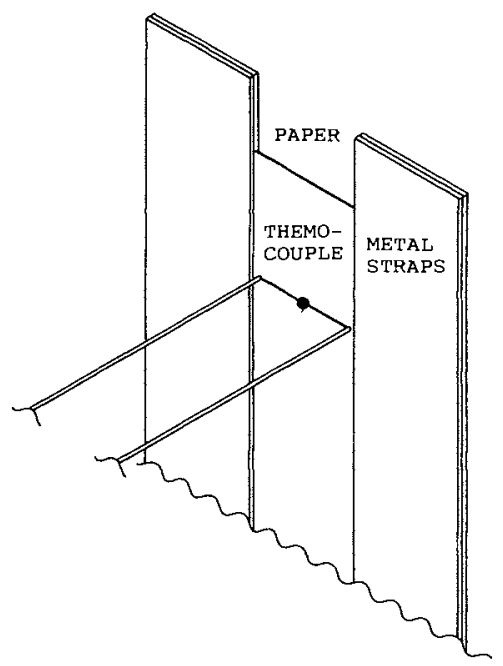

FIGURE I Experimental arrangement

Aspects of a spreading flame are illustrated in Fig.2. A luminous yellow flame follows a blue leading flame edge. The paper sheet surface becomes dry at about $4 \mathrm{~mm}$ behind the leading edge of the blue flame. In this dry zone, the paper sheet surface is white, and then paper turns into brown behind a line about $9 \mathrm{~mm}$ from the leading flame edge, where pyrolysis reactions would occur.

The pyrolysis zone was observed to tear into a few parts at about $19 \mathrm{~mm}$ behind the leading flame edge, and became ash. The distance between the leading edges of the flame and pyrolysis zone or dry zone increased as the boiling temperature of soaking liquid decreased. Since the flash temperature of octane $\left(13^{\circ} \mathrm{C}\right)$ was below the initial temperature, a premixed

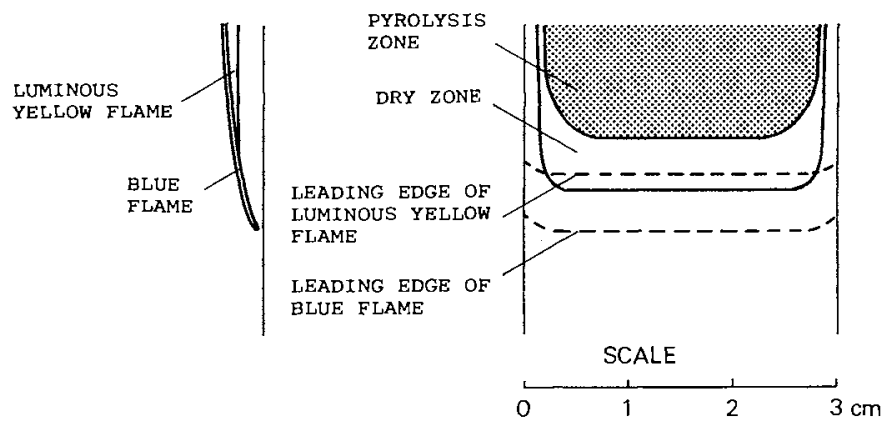

FIGURE 2 Aspects of a spreading flame over a undecane-soaked paper sheet. $\mathrm{d}=0.23 \mathrm{~mm}, \alpha=90^{\circ}, \rho=1 \mathrm{~g} / \mathrm{cm}^{3}$. 


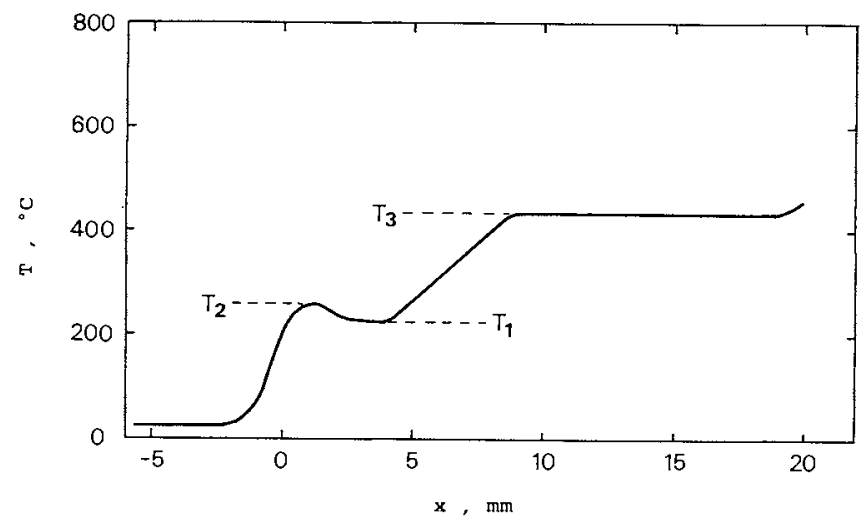

FIGURE 3 Temperature profile of the surface of a undecane-soaked paper sheet. $\mathrm{d}=0.23 \mathrm{~mm}, \alpha=90^{\circ}, \rho=1 \mathrm{~g} / \mathrm{cm}^{3}$.

flame was expected to propagate through a flammable mixture layer on the paper surface. In these experiments, however, propagation of a flame, whose velocity was comparable to a premixed flame, along the paper surface was not observed.

Figure 3 represents a profile of the temperature $T$ along the surface. Temperature starts to increase at $x \simeq-2 \mathrm{~mm}$ and continues to increase to $T=T_{2}$ at $x \approx 1 \mathrm{~mm}$. Then $T$ gradually decreases to $T=T_{1}$ at the leading edge of the dry zone $(x \sim 4 \mathrm{~mm})$ and again increases to $T=T_{3}$ at the pyrolysis zone ( $9 \mathrm{~mm} \leq \mathrm{x} \leq 19 \mathrm{~mm}$ ) where $\mathrm{T}$ is constant. Behind the pyrolysis zone $(x \geq 19 \mathrm{~mm})$, the paper becomes ash and $\mathrm{T}$ increases again.

Figure 4 represents position-time diagrams. It is seen that the leading edges of the flame, dry zone, and pyrolysis zone spread at almost the same and constant rate with constant distance separations.

\section{Flame spread rates}

The variation of flame spread rate $\mathrm{V}$ with the paper sheet thickness is shown in Fig.5. In the cases of flame spread over paper sheets soaked with octane, nonane, and decane, $\mathrm{V}$ is almost proportional to the reciprocal of $\mathrm{d}$ for $\mathrm{d} \leq 0.26 \mathrm{~mm}$. This proportional relation can not extend to the cases for $\mathrm{d}=0.40 \mathrm{~mm}$ or $0.68 \mathrm{~mm}$. The deviation from this relation increases as the boiling temperature of soaking liquid decreases. On the other hand, V over paper sheets soaked with undecane, dodecane and tridecane is almost proportional to the reciprocal of $\mathrm{d}$ throughout all the range of $d$ examined in the experiments.

The variation of the mass burning rate $m(=\rho d V)$ with $d$ is shown in Fig.6. For paper sheets soaked with octane, nonane, and decane, $m$ increases with $d$, while for those soaked 


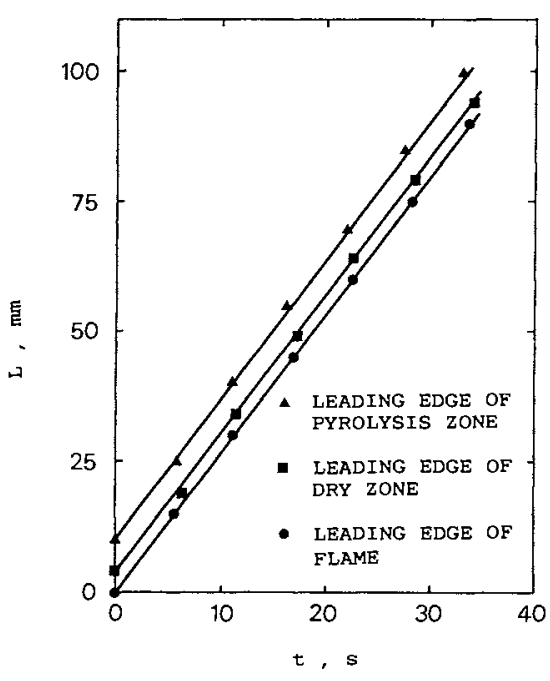

FIGURE 4 Position - time diagrams which represent spread rates of the leading edges of the flame, the dry zone, and the pyrolysis zone over a undecane-soaked paper sheet. $\mathrm{d}=0.23 \mathrm{~mm}, \alpha=90^{\circ}, \rho=1 \mathrm{~g} / \mathrm{cm}^{3}$.

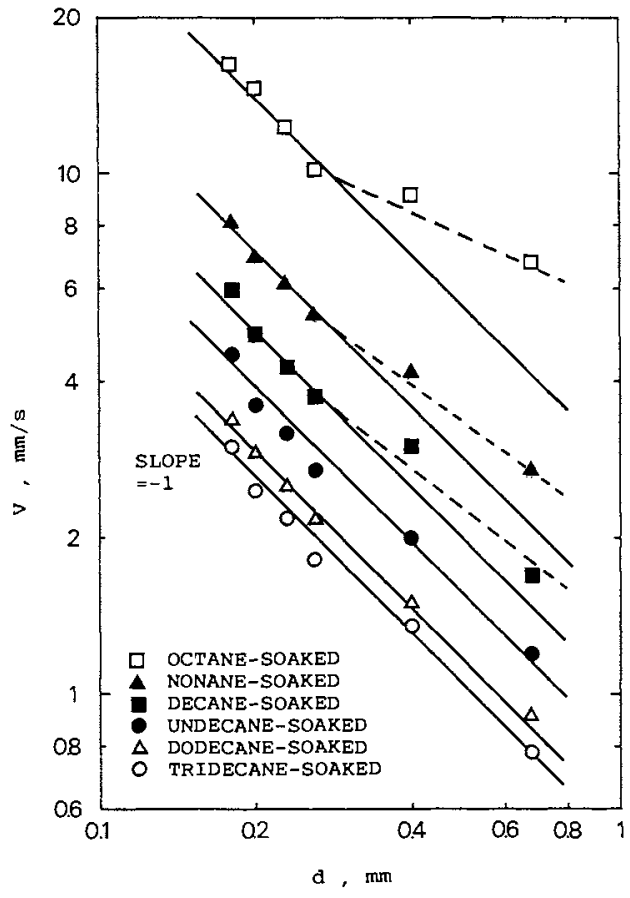

FIGURE 5 Variation of flame spread rate with paper sheet thickness.

$\alpha=90^{\circ}, \rho=1 \mathrm{~g} / \mathrm{cm}^{3}$.

with undecane, dodecane, and tridecane, $m$ is almost independent of $d$. It is seen that the relation between $\mathrm{V}$ and $\mathrm{d}$ for flame spread over paper sheets soaked with a lower boiling temperature liquid is similar to that over a thick combustible solid. On the other hand that over paper sheets soaked with a higher boiling temperature liquid is similar to that over a thin one.

For various values of $\rho$, flame spread rates are shown in Fig.7. A slight decrease in V with increase in density over nonane-soaked paper sheets or decane-soaked paper sheets was observed, while $\mathrm{V}$ over undecane-soaked paper sheets was almost constant

Figure 8 represents the variation of $m$ with $\rho$. It is seen that $m$ increases with $\rho$.

It is well known that the flame spread rate depends on the ambient air stream which varies with the inclined angle $\alpha$ of the combustible solid surface. Figure 9 shows the dependence of $V$ on $\alpha$. Horizontal flame spread was so unstable that quantitative measurement could not be performed. It is seen that $\mathrm{V}$ increases as $\alpha$ decreases.

The following relation has been proposed for the explanation of flame spread 


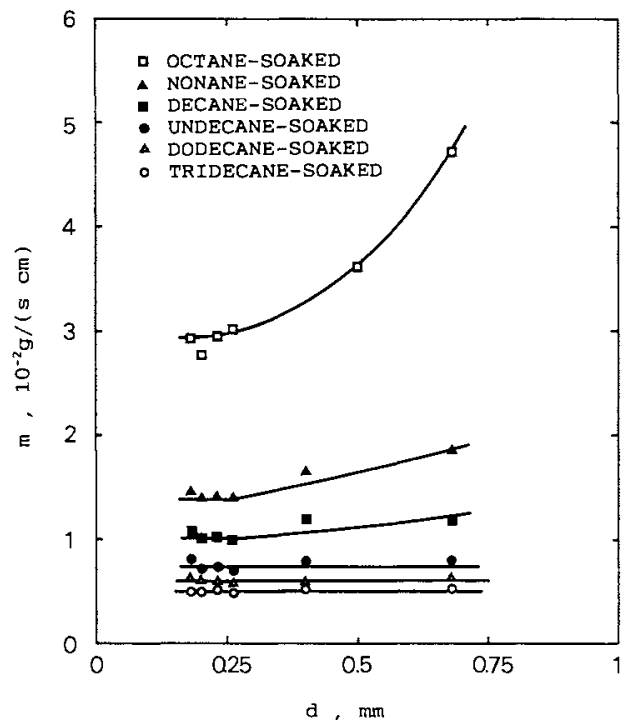

FIGURE 6 Variation of mass burning rate with paper sheet thickness $\alpha=90^{\circ}, \rho=1 \mathrm{~g} / \mathrm{cm}^{3}$.

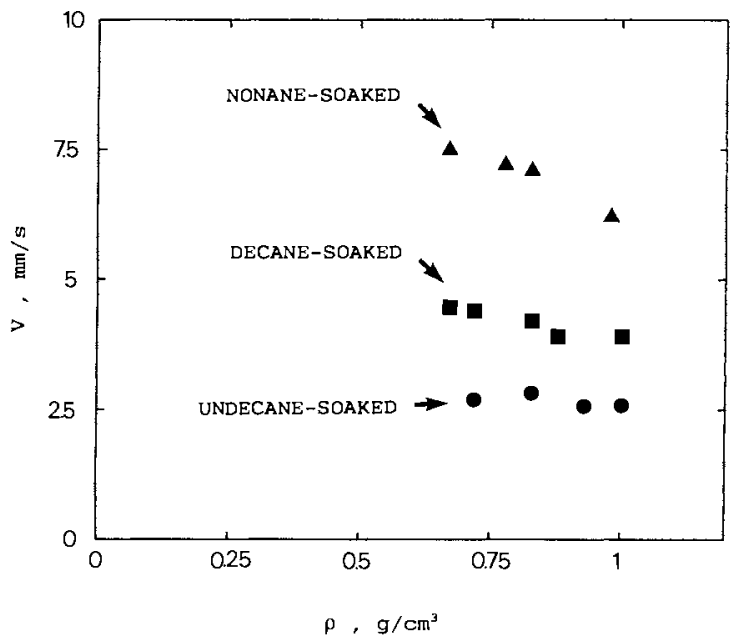

FIGURE 7 Variation of flame spread rate with density. $\mathrm{d}=0.23 \mathrm{~mm}, \alpha=90^{\circ}$. 


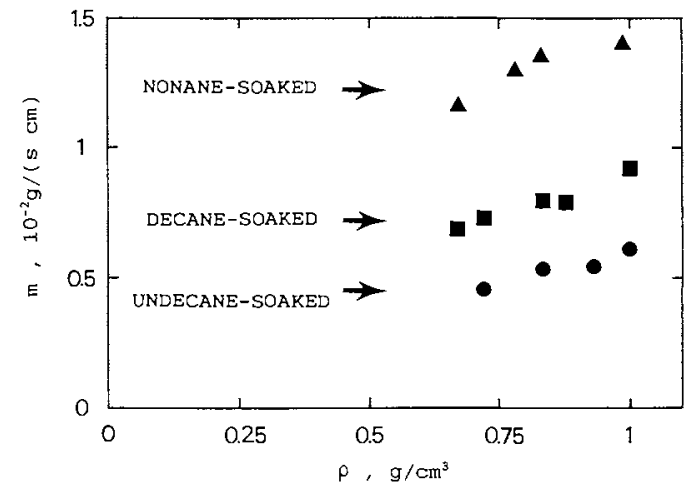

FIGURE 8 Variation of mass burning rate with density. $\mathrm{d}=0.23 \mathrm{~mm}, \alpha=90^{\circ}$.

mechanisms $[1,4,7]$

$\mathrm{V} \sim\left(\mathrm{T}_{\mathrm{p}}-\mathrm{T}_{\mathrm{i}}\right)^{-1} \quad$ for a thin combustible solid

$\mathrm{V} \sim\left(\mathrm{T}_{\mathrm{p}}-\mathrm{T}_{\mathrm{i}}\right)^{-2} \quad$ for a thick combustible solid

where $T_{p}$ pyrolysis temperature, $T_{i}$ initial temperature. In the present study, a boiling

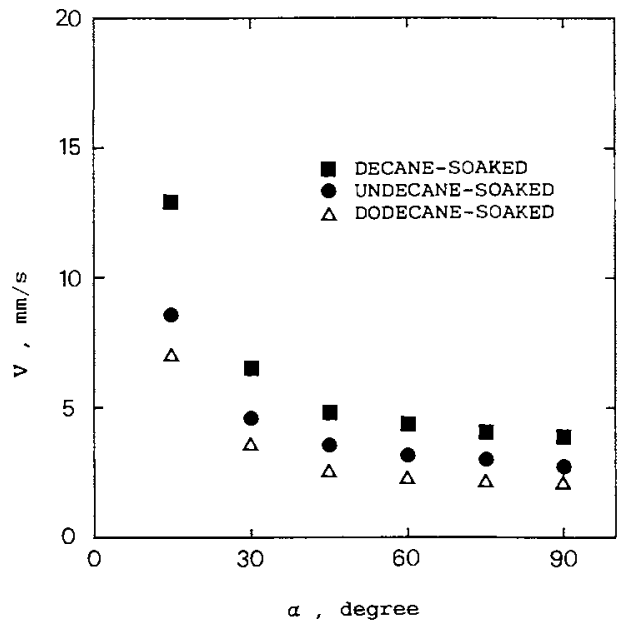

FIGURE 9 Variation of flame spread rate with inclined angle. $\mathrm{d}=0.23 \mathrm{~mm}, \rho=1 \mathrm{~g} / \mathrm{cm}^{3}$. 


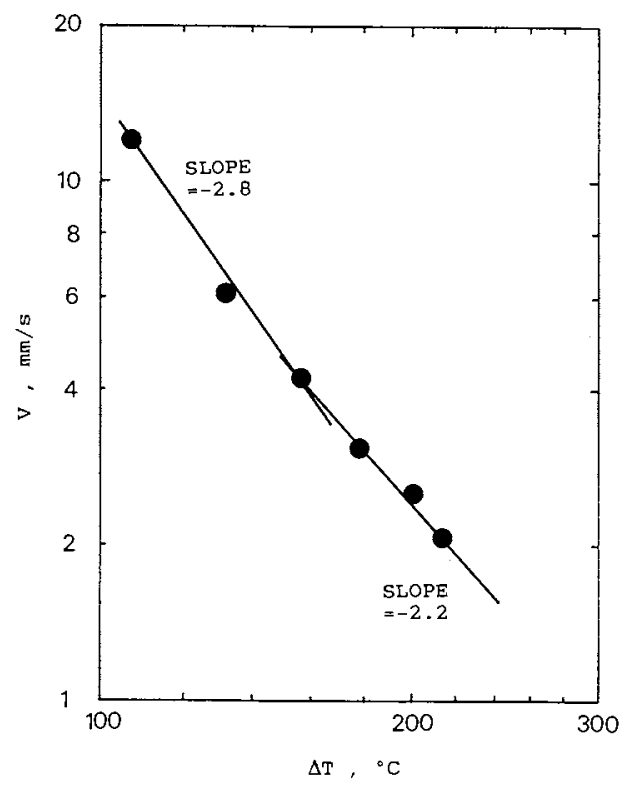

FIGURE 10 Variation of flame spread rate with $\Delta \mathrm{T}$. $\mathrm{d}=0.23 \mathrm{~mm}, \alpha=90^{\circ}, \rho=1 \mathrm{~g} / \mathrm{cm}^{3}$.

temperature $T_{b}$ of soaking liquid seems to be appropriate to assume as the gasification temperature of solid which corresponds to pyrolysis temperature $T_{p}$ of solid.

Figure 10 represents the variation of flame spread rate with $\Delta \mathrm{T}\left(=\mathrm{T}_{\mathrm{b}}-\mathrm{T}_{\mathrm{i}}\right)$. It is seen that $\mathrm{V}$ depends on $\Delta \mathrm{T}$. As $\Delta \mathrm{T}$ decreases, $\mathrm{V}$ increases. Also the increasing rate of $\mathrm{V}$ with decreasing of $\Delta \mathrm{T}$ becomes large as $\Delta \mathrm{T}$ decreases. The data obtained from the experiments were correlated using the relationship,

$\mathrm{V} \sim\left(\mathrm{T}_{\mathrm{b}}-\mathrm{T}_{\mathrm{i}}\right)^{-\mathrm{n}}$

The value of $\mathrm{n}$ is 2.8 for $\Delta \mathrm{T}$ between 100 and $160^{\circ} \mathrm{C}$, while it is 2.2 for $\Delta \mathrm{T}$ between 160 and $220{ }^{\circ} \mathrm{C}$. This relation is much different from the relation for flame spread over a thin combustible solid and also slightly different from that over a thick combustible solid. This result implies that the flame spread mechanisms depend not only on the combustible solid thickness but also on its gasification properties. 


\section{CONCLUSIONS}

An experimental study of flame spread over the surface of a filter paper sheet soaked with a combustible liquid was performed to obtain knowledge of the effects of gasification properties of a solid combustible on flame spread phenomena and the following conclusions were derived.

1. Flame spread rate $\mathrm{V}$ increases as the boiling temperature $T_{b}$ of soaking liquid decreases. The increasing rate of $V$ with decreasing of $T_{b}$ becomes large as $T_{b}$ decreases.

2. Flame spread rate decreases as the paper sheet thickness $d$ increases. The decreasing rate of $V$ with increasing of $d$ becomes small as $T_{b}$ decreases or $d$ increases.

\section{REFERENCES}

1. de Ris, J. N., "Spread of a Laminar Diffusion Flame", 12th Sym.(Int.) on Comb., pp.241-252, The Combustion Institute, Pittsburgh, Pa., 1969.

2. Williams, F. A., "Mechanisms of Fire Spread", 16th Sym.(Int.) on Comb., pp. 12811294, The Combustion Institute, Pittsburgh, Pa., 1977.

3. Fernandez-Pello, A. C. and Hirano, T., "Controlling Mechanisms of Flame Spread", Comb. Sci. Technol, 32: 1, 1-31,1983.

4. Aseeva, R. M. and Zaikov, G. E., "Flammability of Polymeric Materials", in Advances in Polymer Science, Vol. 70, pp. 171-229, Springer-Verlag, Berlin, 1985.

5. Hirano, T., "Physical Aspects of Combustion in Fires", in Fire Safety Science, Proc. 3rd Int. Symp., ed. G. Cox and B. Langford, pp. 27-44, Elsevior, London, 1991.

6. Pitts, W. M., "Wind Effects on Fires", Prog. Energy Comb. Sci., 17: 2, 83-134, 1991

7. Wichman, I. S., "Theory of Opposed-flow Flame Spread", Prog. Energy Comb. Sci., 18: 6, 553-593, 1992.

8. Hirano, T., Noreikis, S. E. and Waterman, T. E., "Postulation of Flame Spread Mechanisms", Comb. Flame, 22: 3, 353-363, 1974.

9. Hirano, T., Noreikis, S. E. and Waterman, T. E., "Measured Velocity and Temperature Profiles Near Flames Spreading Over a Thin Combustible Solid", Comb. Flame, 23: 1, 83-96, 1974.

10. Kashiwagi, T. and Newman, D. L., "Flame Spread over an Inclined Thin fuel Surface", Comb. Flame, 26: 2, 163-177, 1976.

11. Ito, A. and Kashiwagi, T., "Characterization of Flame Spread over PMMA Using Holographic Interferometry Sample Orientation Effects", Comb. Flame, 71:2, 189-204, 1988 .

12. Weber, R. O. and de Mestre, N. J., "Flame Spread Measurement on Single Ponderosa 
Pine Needles: Effects of Sample Orientation and Concurrent External Flow", Comb. Sci. Technol., 70: 1, 17-32, 1990.

13. Hirano, T. and Sato, K., "Effects of Radiation and Convection of Gas Velocity and Temperature Profiles of Flames Spreading Over Paper", 15th Sym.(Int.) on Comb., pp. 233-241, The Combustion Institute, Pittsburgh, Pa., 1975.

14. Hirano, T. and Tazawa, K., "A Further Study on Effects of External Thermal Radiation on Flame Spread over Paper", Comb. Flame, 32: 1, 95-105, 1978.

15. Hirano, T., Sato, K. and Tazawa, K., "Instability of Downward Flame Spread over Paper in an Air Stream", Comb. Flame, 26: 2, 191-200, 1976.

16. Sato. K., Miki, K. and Hirano, T., "Flame Spread Over Paper in an Air Stream With a Velocity Change", J. Heat Transfer, 106: 4, 707-712, 1984.

17. Takeno, K. and Hirano, T., "Delayed Extinction of Flames Spreading Downward over Paper Sheets", Fire Safety Science, Proc. 2nd Int. Symp., ed. T. Wakamatsu, Y. Hasemi, A. Sekizawa, P. G. Seeger, P. J. Pagni and C. E. Grant, pp. 97-105, Hemisphere, New York, 1989.

18. Suzuki, T., Kawamata, M. and Hirano, T., "Flame Spread over Fuel Soaked Sand in an Opposed Air Stream", Fire Safety Science, Proc. 2nd Int. Symp., ed. T. Wakamatsu, Y. Hasemi, A. Sekizawa, P. G. Seeger, P. J. Pagni and C. E. Grant, pp. 199-208, Hemisphere, New York, 1989.

19. Campbell, A. S., "Fire Spread Over Paper", J. Fire Flammabl., 5: 3, 167-178, 1974.

20. Hirano, T. and Tazawa, K., "Effect of Thickness on Downward Flame Spread over Paper", Bull. JAFSE, 26:1, 7-13, 1976(in Japanese).

21. Suzuki, T. and Hirano, T, "Flame Spread Over Paper Soaked with a Combustible Liquid", Fire Science and Technology, Proc. 1st Asian Conference, ed. Fan W. and Fu Z. pp. 455-460, International Academic Publishers, Beijing, 1992.

22. Takeno. K. and Hirano, T., "Flame Spread Over Porous Solids Soaked with a Combustible Liquid", 21 th Sym.(Int.) on Comb., pp. 75-81, The Combustion Institute, Pittsburgh, Pa., 1986.

23. Takeno, K. and Hirano, $\mathrm{T}$., "Behavior of Combustible Liquid Soaked in Porous Beds During Flame Spread", 22th Sym.(Int.) on Comb., pp. 1223-1230, The Combustion Institute, Pittsburgh, $\mathrm{Pa}, 1988$.

24. Sekiyu Gakkai ed, Sekiyu Jiten, Asakura Shoten, Tokyo, 1966 (in Japanese) 
